\title{
A Rare Case of Adult Onset Partial Unilateral Lentiginosis
}

\author{
Işıl Göğem Imren ${ }^{1 *}$, Fatma Aslan Yay², Hatice Meral Ekșioğlu ${ }^{3}$ and Şeniz Duygulu ${ }^{1}$ \\ ${ }^{1}$ Department of Dermatology, Faculty of Medicine, Pamukkale University, Denizli, Turkey \\ ${ }^{2}$ Department of Pathology, University of Health Sciences Ankara Research and Training Hospital, Turkey \\ ${ }^{3}$ Department of Dermatology, University of Health Sciences Ankara Research and Training Hospital, Turkey
}

Submission: April 04, 2020; Published: April 13, 2020

*Corresponding author: Işıl Göğem Imren, Department of Dermatology, Faculty of Medicine, Pamukkale University, Denizli, Turkey

\begin{abstract}
Segmental lentiginous is a rare pigmentation disorder with typical lentigo histopathology characterized by unilateral and dermatomal localization of multiple, brown macules on skin. We present a 55-year old female patient with adult onset nonsendromic form of partial unilateral lentiginosus on her right side of trunk. This bening lesion, which includes pigmenter mosaicism in its pathogenesis, can be found as part of syndromes or can be seen sporadically as it is here.
\end{abstract}

Keywords: Pigmentary Disorders; Partial Unilateral Lentiginosus; Pigmenter Mosaicism

\section{Introduction}

Segmental lentiginous is a rare pigmentation disorder with typical lentigo histopathology characterized by unilateral and dermatomal localization of multiple, light brown, grouped macules on normal-looking skin [1]. Generally, lesions are present at birth or noticed during childhood but some adult cases described $[1,2]$. Although treatment is not necessary because of bening nature, many patients with facial lesion complain of cosmetically disfiguring effect [1-3].

\section{Case Report}

A 55-year-old female patient presented to clinic for spots on right half of her body. When she was 25 years old during her first pregnancy period, she first noticed these spots on her right breast. The patient says that these spots gradually increase and spread to the abdomen and back in following years. There was no family history of similar cutaneous features. She did not have systemic disease and medication she used regularly. Dermatological examination revealed multiple brown macules in the size of 1-15 mm located on the right breast, abdomen and back. These macules ended abruptly at the midline (Figure 1). There were no other findings such as axillary freckles and neurofibromas to suggest neurofibromatosis. There was no psychomotor or musculoskeletal development abnormality. Results of routine laboratory examinations, including complete blood cell count, $\mathrm{TSH}$, liver and kidney function tests were within Normal limits. Her ophthalmologic, and neurologic, evauation were normal. Histologic examination of a biopsy specimen from a small pigmented macule under the breast skin shows lentigo findings characterized by increased basal pigmentation, melanocytic hyperplasia and prolonged rete ridge (Figure 2). Based on these findings, the patient was diagnosed as partial unilateral lentiginous.

\section{Discussion}

Segmental or partial lentiginosis, lentiginous mosaicism are other terms used to describe this disease. The distribution of multiple lentigines is generally unilateral, separated from the midline with a sharp border, can be held as a single dermatome or spread to several dermatomal areas. Although it can be seen anywhere on the body, including the face, neck, trunk and extremities, it is more common in the upper extremity. Generalized forms that hold one half of the whole body are called complete unilateral lentiginosis. Generally, lesions are present at birth or 
noticed during childhood but some adult cases described [1,2]. Although the pathogenesis is not fully known, somatic mosaicism hypothesis has been proposed during embryonic development, possibly due to limited mutation to neural crest melanoblasts. Since it is seen in somatic cells, its transmission to future generations is not seen with germ cells [2,4]. There are several developmental pigmentary genes such as SNAI2, KITLG, EDNRB, EFNB1, EFNB2 related to pigmenter mosaisizm, role in neural crest differentiation and melanoblast migration [4].

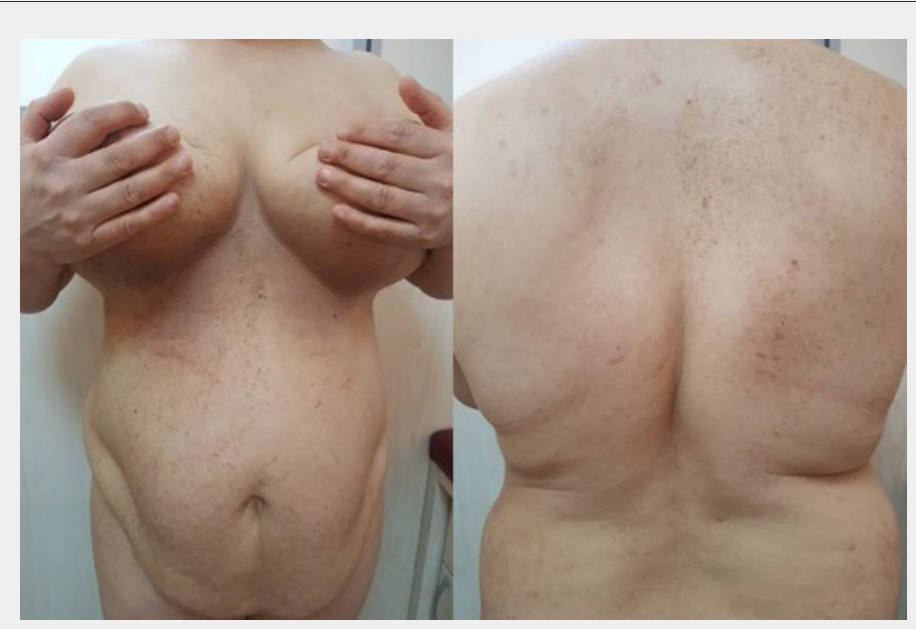

Figure 1: Multiple lentigines in the right half of the body.

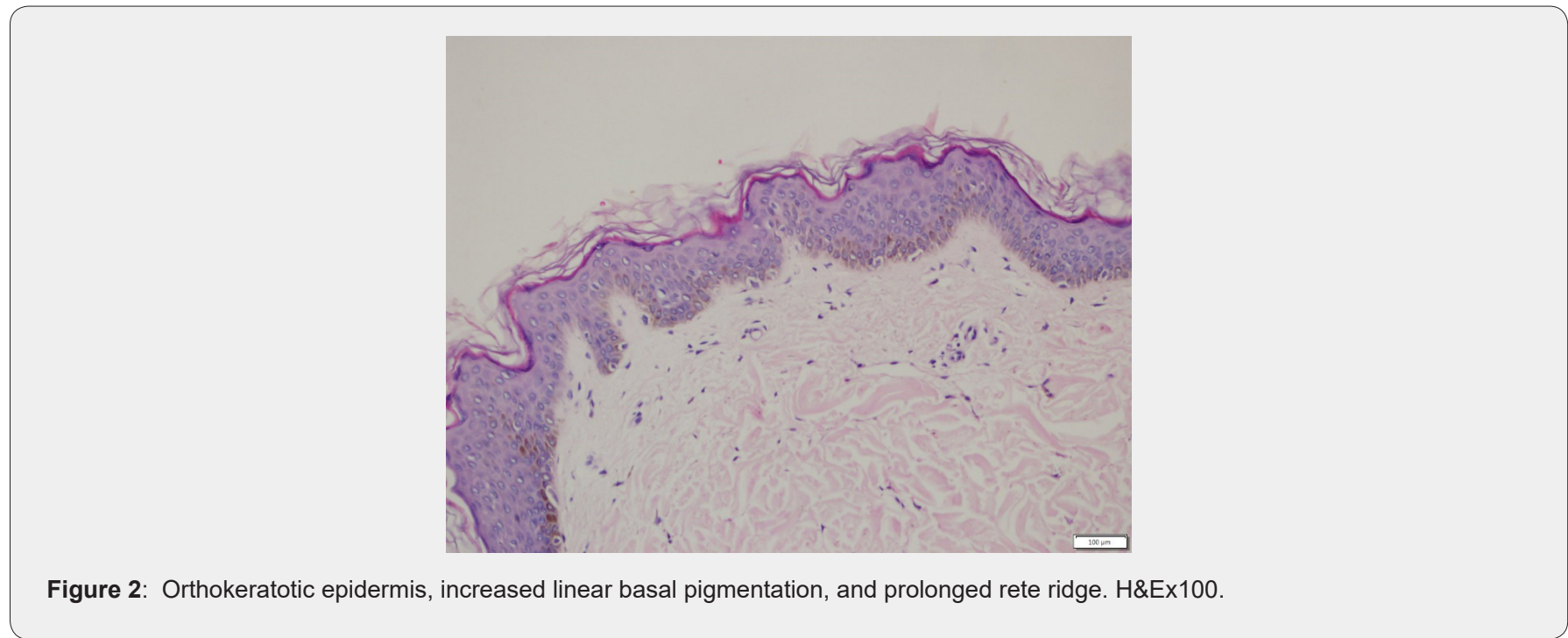

Some segmental lentiginous cases have been shown to be associated with segmental neurofibromatosis and segmental Café au lait spots, which may be associated with somatic mosaism and postzigotic mutations. Neurological and opthalmologic pathologies were also found in a small number of patients [1-3]. Multiple lentigines in one area of the body can be seen in central facial lentiginous, Peutz-Jeghers syndrome, Leopard syndrome. These conditions are inherited OD and are associated with additional developmental defects [2,3]. Additional findings such as mental retardation, ipsilateral cerebrovascular abnormalities accompanied by focal epilepsy, Lisch nodules on the iris, and congenital cataracts were also found in a some patients with complete segmental lentiginous [3]. In our case, no additional pathology was detected.

Another differential diagnosis, nevus spilus maculosa is a lesion characterized by tan to light brown patch multiple small darker brown macules superimposed, in lentigo histopathology with an increase in basal pigmentation and can be seen segmentally or zosteriform. It is important to be diagnosed in the following years as it carries a risk of developing melanoma. Nevus spilus maculosa can be accompanied by ipsilateral dysesthesia, muscular weakness and hyperhidrosis as part of Phakomatosis pigmentokeratotica syndrome [5]. The treatment is not necessary except cosmetic concerns because of bening nature of PUL. Cases 
where the 1064-nm Q-switched Nd:YAG laser has been successfully used for treatment have been reported, and recurrences have not been observed in these cases [6,7]. In our case, we highlight importance of somatic mosaicism in the differential diagnosis of pigmentation disorders due to the presence of lentigines on dermatomal localization, histological examination consistent with lentigo as partial unilateral lentiginous.

\section{References}

1. Schaffer JV, Lazova R, Bolognia JL (2001) Partial unilateral lentiginosis with ocular involvement. J Am Acad Dermatol 44(2): 387-390.

2. Toelle SP, Boltshauser E, Wirth MG, Itin P(2006) Association of lentiginous mosaicism and congenital cataract in a girl. Eur J Dermatol 16(4): 360-362.
3. Lee WS, Yoo MS, Ahn SK, Won JH (1995) Partial unilateral lentiginosis associated with segmental neurofibromatosis. J Dermatol 22(12): 958959.

4. Taibjee SM, Bennett DC, Moss C (2004) Abnormal pigmentation in hypomelanosis of Ito and pigmentary mosaicism: the role of pigmentary genes. Br J Dermatol 151(2): 269-282.

5. Corradin MT, Cacitti V, Giulioni E, Patriarca MM, Vettorello A (2015) Nevus Spilus: A Review of the Literature. SM Dermatolog J 1(1): 1003.

6. Hur H, Kim YR, Shim DT (2017) The treatment of café au lait spot, partial unilateral lentiginosis and Becker's nevus using a high fluence 1,064-nm Q-switched Nd:Yag laser. J Clin Cosmet Dermatol 1(2).

7. Kim EH (2017) A Case of Facial Partial Unilateral Lentiginosis Treated with Low-Fluence 1,064 nm Q-Switched Neodymium-Doped Yttrium Aluminum Garnet Laser. Case Rep Dermatol 9(2): 30-34.

This work is licensed under Creative Commons Attribution 4.0 License DOI: $10.19080 / J O J D C .2020 .02 .555594$ 